\title{
RESENHA
}

\section{Dos Pântanos à Escassez: Uso da água e Conflito na Baixada dos Goytacazes}

Dos Pântanos à Escassez: Uso da água e Conflito na Baixada dos Goytacazes é o resultado de uma dissertação de mestrado apresentada no Instituto de Planejamento Urbano e Regional da Universidade Federal do Rio de Janeiro em abril de 2003. O livro traz para o leitor uma problemática pouco discutida e até certo modo desconhecida para alguns, acerca dos conflitos e das relações de poder em torno do uso da água naquele território, assim como das profundas transformações do ambiente natural iniciadas desde a época do Brasil colônia.

Tal temática procura contribuir para novos debates e estudos da região como também de outros ambientes de mesma característica geológico-geomorfológica, a exemplo das planícies deltaicas do Rio Doce e do Rio São Francisco, que passam atualmente por problemas semelhantes. Os principais atores envolvidos no conflito são as usinas de cana-de-açúcar, os proprietários de terras, os pescadores e as instituições públicas que disputam um território materializado hoje em uma planície deltaica "rasgada" por centenas de quilômetros de canais e diques e por um total estado de desequilíbrio hidrológico praticamente irreparável.

O trabalho foi estruturado em três grandes capítulos, todos eles envolvendo a questão do uso da água. O primeiro, intitulado "Resgate Histórico", faz uma breve caracterização fisiográfica da região com base no estudo pioneiro de Alberto Lamego. Descreve assim os principais processos de formação da planície deltaica do rio Paraíba do Sul ao longo do Quaternário, configurado num ambiente peculiar de lagoas, lagu- 
nas, brejos em que parte dele "era" naturalmente sujeito a inundações nos períodos de cheias do rio.

Na seqüência desse primeiro capítulo, Carneiro recorre a uma criteriosa investigação histórica, desde o Brasil Colonial até finais da década de 70, revelando a baixada dos Goytacazes como uma região estratégica que tinha como principal característica a vocação agrícola, com extrativismo, diversas culturas agrícolas e a pecuária, anterior à monocultura canavieira. É a partir do final do século XVII que a baixada passa a estar sujeita aos grandes projetos de engenharia, com a execução da primeira grande obra hidráulica abrindo um canal que permitiu o rápido escoamento das águas das chuvas para o mar a fim de salvaguardar as lavouras, criações de cavalo e gado. Posteriormente, ocorreu a construção do canal Campos-Macaé, iniciada em 1844 e inaugurada em 1861, com uma extensão de 96 quilômetros, 11 metros de largura e 1,30 de profundidade, interligando as bacias do rio Paraíba do Sul, da lagoa Feia e do rio Macaé. Constituiu-se numa obra fundamental para o aumento da produção açucareira de Campos e, por outro lado, resultou no processo de drenagem de lagoas e até no desaparecimento de outras. No período de 1883 a 1933 foram constituídas mais oito comissões ocorrendo no final desse período o processo de "centralização de unidades produtivas" com a modernização da agroindústria açucareira reduzindo em 32 os modernos engenhos centrais e usinas em substituição dos 400 engenhos antigos.

O período que vai do ano de 1935 até meados da década de 1970 foi marcado pela implantação dos grandes projetos de drenagem decorrentes do novo contexto políticoinstitucional da revolução de 30, destacando-se a criação do Departamento Nacional de Obras de Saneamento (DNOS), em 4 de julho de 1940, através do Decreto-Lei ${ }^{\circ}$ 2.367. Em seu texto legal o DNOS previa um amplo espectro de atribuições, incluindo a responsabilidade pela política nacional de saneamento geral e básico (rural e urbano), defesa contra inundações, controle de enchentes, erradicação de doenças, recuperação de áreas para aproveitamento agrícola, instalação de indústrias e fábricas, etc. Em 13 de julho de 1962, com a Lei $n^{\circ} 4.089$, o órgão foi transformado em autarquia, tendo a partir de então uma autonomia financeira e administrativa. Sua área de atuação abrangia todo o território brasileiro, porém foi na baixada fluminense, particularmente na baixada de Campos dos Goitacazes, área piloto, que foi notada a maior atuação com a construção de vários canais que, com o passar dos anos, provocou uma série de modificações na dinâmica hídrica da região com o propósito de atender, sobretudo, as demandas das usinas açucareiras.

Outros fatores importantes que potencializaram a região como grande produtora de cana-de-açúcar foram: o processo de pulverização fundiária das pequenas propriedades influenciando, sobretudo, a agricultura familiar, induzindo-a à especialização da produção de cana e, definitivamente, colocando um fim no cultivo de outras lavouras, subordinando os pequenos agricultores às usinas. A pavimentação da rodovia Campos-Niterói em 1950 (atual BR 101) possibilitou o escoamento mais eficiente do açúcar, reduzindo a dependência da Estrada de Ferro Leopoldina. Outro importante 
acontecimento foi o início do processo de concentração industrial e das diversas políticas agrícolas voltadas para o aumento da produção industrial do açúcar e do álcool, a partir da criação, em 1975, do Programa Nacional do Álcool (Proálcool).

Portanto, o conjunto dessas ações promoveu o aumento significativo da área produtiva no município de Campos, refletindo-se nos censos agropecuários em três diferentes momentos. No primeiro, na década de 1920, a área cultivada era inferior de 3000 ha, com uma produção estimada em 73.000 toneladas de cana. No período seguinte, de 1940 a 1960, a área média colhida passou a ser de 76.000 ha com uma produção média de 1.966 .330 toneladas. $\mathrm{E}$, no período seguinte, correspondente à década de 1970, a área média utilizada pela lavoura canavieira atingiu mais de 127.000 ha com uma produção média de 4.357.028 toneladas. Ou seja, esse expressivo aumento da área cultivada deu-se a partir do dessecamento da planície e, conseqüentemente, com o aumento das terras cultiváveis.

O capítulo dois "A Emergência dos Conflitos" focaliza também as grandes obras de engenharia, agora para promover a irrigação das áreas cultivadas e atender à demanda das modernas usinas de cana-de-açúcar, que aumentaram substancialmente a capacidade de produção, encetando disputas pelo uso da água. O autor segue o texto contextualizando o final da década de 1970 e os anos 1980 , revelando o novo momento por que passou a região, marcada por grandes projetos de irrigação, nos quais a água adquire um novo sentido, passando a ser fundamental para o aumento da produtividade agroindustrial canavieira, desencadeando, no final da década de 1980, uma série de conflitos que colocaram em evidência os vários projetos de apropriação dos recursos hídricos.

Nesse período são implementados também diversos planos, programas e projetos na região Norte fluminense, de forma a promover o desenvolvimento agroindustrial canavieiro até o ano de 1984, entre eles o Programa Especial do Norte Fluminense (Prodenor); Programa Nacional do Álcool (Proálcool); Programa Nacional de Melhoramento da cana-de-açúcar (Planasulcar); Programa de Aproveitamento de Várzeas (Provárzeas); Projetos Demonstrativos de Irrigação, através de convênios entre ministérios e cooperativas; Plano Estratégico de Aproveitamento Hidro-agricola da Baixada e Tabuleiro do Norte Fluminense; Projetos de financiamento de Usinas; Plano diretor de Várzeas do Norte Fluminense (Provárzeas/NF).

O autor mostra o extraordinário crescimento da área irrigada no município de Campos nesse período, saltando de 922 ha em 1970 para 7.746 ha em 1980 e, também, o crescimento no número de estabelecimentos irrigados, que passa de $17 \mathrm{em} 1970$ para 908 em 1980. O autor fecha o capítulo mostrando que a difusão da irrigação na Baixada Campista ocorreu de forma concentrada nas mãos de poucos, com o número de propriedades com acesso à irrigação abaixo de $10 \%$ do total de estabelecimentos.

O terceiro capítulo, "O Período da Escassez", discute o atual quadro sócio-ambiental decorrente das intervenções / obras anteriores, marcado pelo crescimento dos conflitos e disputas pela apropriação das águas. O autor situa o final da década de 1980, 
evidenciada pela crise e o fim do modelo autoritário da máquina administrativa do governo, ocorrendo a partir daí uma ampla reforma com a extinção de ministérios, fundações e autarquias, entre elas o próprio DNOS.

A partir desse momento os proprietários rurais e usineiros apropriaram-se, de fato, do controle e do destino da água na região, operando comportas, barrando os cursos d'água de acordo com seus interesses, a partir de uma condução privada do sistema de canais. Paralelamente, ocorreu a organização dos segmentos sociais sensíveis a uma condução mais democrática da infraestrutura hídrica construída pelo DNOS, defendendo uma nova gestão do uso da água, apoiados pelas colônias de pescadores, resultando em novos conflitos de usos na região.

É importante ressaltar que, dentro da complexidade envolvida nas questões de disputas em torno da água, o autor analisou apenas os conflitos concernentes aos segmentos que usam a água como insumo de atividades econômicas, com o destaque para o segmento agroindustrial (envolvimento das usinas e produtores rurais) e segmentos de pescadores e pequenos produtores rurais.

Ao recorrer a esse criterioso apanhado histórico, desde o Brasil colônia, com o propósito de melhor entender e explicar o contexto atual do território pesquisado, o autor revela para nós um cenário pouco diferenciado daquela época, com uma região sempre voltada para os interesses do uso agrícola da monocultura de cana, sujeita a diversas intervenções na dinâmica hídrica a partir dos gigantescos projetos de drenagens e irrigação. É nessa seqüência de fatos que uma paisagem de terras úmidas, pantanosas, com inúmeras lagoas permanentes e temporárias, transforma-se em área de terras ressecadas e, em alguns locais, salinizadas, sobretudo nos períodos de baixa pluviosidade, fato agravado por disputas de interesses e onde prevalecem hegemonicamente os grandes proprietários de terras e donos de usinas, defensores do atual modelo agrícola intensivo de irrigação.

Enfim, o que se presencia hoje na Baixada dos Goytacazes é a pratica de uma lógica fundada desde o final do século XVII em prol da expansão e valorização fundiária que veio se tornar um padrão no século XX, porém substancialmente aprofundada.

André Luiz Nascentes Coelho UFES/PPGG-UFF 